\title{
Limbic Encephalitis Manifesting as Selective Amnesia and Seizure-like Activity: A Case Report
}

\author{
So-Yeon Kim ${ }^{1}$, Yoo Hyun Um ${ }^{1}$, Sung Chul Lim², Jong-Hyun Jeong ${ }^{1}$ \\ Departments of ${ }^{1}$ Psychiatry and ${ }^{2}$ Neurology, College of Medicine, The Catholic University of Korea, Seoul, Korea
}

\begin{abstract}
Limbic encephalitis (LE) is characterized by short-term memory loss, disorientation, agitation, seizures, and histopathological evidence of medial temporal lobe inflammation. Leucine-rich, glioma inactivated 1 (LGl-1) is an auto-antigen associated with LE. We report a 37-year-old male patient with LGI-1-related LE who presented with recurrent episodes of selective amnesia, seizure-like activity, confusion, and personality change. His symptoms were significantly improved with steroid therapy. Thorough differential diagnosis with consideration for autoimmune encephalitis should be in patients with presentation of symptoms, such as memory impairment, personality change and seizure-like activity, especially when other neurological diagnoses are excluded.
\end{abstract}

KEY WORDS: Anti-LGI-1 antibody encephalitis; Neuropsychiatric symptoms; Steroid therapy.

\section{INTRODUCTION}

Encephalitis is an acute inflammation in the brain that is characterized by presentation of diffuse or focal presentation of neuropsychiatric symptoms. Accurate diagnosis and adequate care are very important for preventing mortality in encephalitis. Incipient pathological changes of encephalitis commonly occur in limbic systems, and can cause neuropsychiatric symptoms including memory impairment, seizure, hallucination, personality change, sleep disturbance and disorientation. Moreover, mental status change and motor disturbances are also caused by encephalitis. ${ }^{1)}$ If infectious, toxic and metabolic causes of encephalitis have been ruled out, autoimmune causes should be assessed. ${ }^{1)}$

In the absence of appropriate diagnosis and care, autoimmune encephalitis (AE) can be fatal or can result in irreversible cognitive impairment, progressive seizure and other various adverse effects. ${ }^{2}$ Therefore, early diagnosis

Received: June 22, 2016/Revised: July 18, 2016

Accepted: July 26, 2016

Address for correspondence: Jong-Hyun Jeong, $\mathrm{MD}, \mathrm{PhD}$ Department of Psychiatry, St. Vincent's Hospital, College of Medicine, The Catholic University of Korea, 93 Jungbu-daero, Paldal-gu, Suwon 16247, Korea

Tel: +82-31-249-7150, Fax: +82-31-248-6758

E-mail: anton3@catholic.ac.kr and intervention in autoimmune limbic encephalitis (LE) is critical. ${ }^{3)}$

AE is caused by auto-antibodies for synaptic proteins including $\mathrm{N}$-methyl-D-aspartate (NMDA) receptor, $\alpha$-amino-3-hydroxy-5-methylisoxazole-4-propionic acid (AMPA) receptor and gamma-aminobutyric acid B $\left(G_{A B A}\right)$ receptor. Especially, the voltage gated potassium channel (VGKC) is the main target of LE related antibodies. ${ }^{4)}$ Two VGKC antibodies target binding sites, namely anti leucine-rich, glioma inactivated-1 (LGI-1) and anti-contactin-associated protein 2 (CASPR2).

Patients with anti-LGI-1 antibody AE present with typical symptoms including memory impairment, confusion and seizure. Moreover, fluid-attenuated inversion recovery (FLAIR) brain magnetic resonance imaging (MRI) shows increased signal intensity in medial temporal lobe, a pathognomic sign of LE. ${ }^{6}$ )

In this case, the patient initially showed selective amnesia and seizure-like movement, but there were no abnormal laboratory and electroencephalogram (EEG) findings. The patient's symptoms improved after immunosuppressive therapy, but two independent tests conducted for the detection of anti-LGI-1 antibody reactivity yielded contrasting results. @ This is an Open-Access article distributed under the terms of the Creative Commons Attribution Non-Commercial License (http://creativecommons.org/licenses/by-nc/4.0)
which permits unrestricted non-commercial use, distribution, and reproduction in any medium, provided the original work is properly cited. 


\section{CASE}

A 37-year-old male patient visited our clinic for selective amnesia and seizure-like movement after sudden headache. Although there were no specific abnormal findings in blood chemistry and EEG, the patient kept complaining about experiencing intermittent sensations of the flow of an electric current. He also experienced seizure-like shivering and repeatedly asked for attention. His amnesia was progressively exacerbated. The patient was hospitalized on April 2015.

Three days after hospitalization, T2 weighted non-enhanced brain MRI showed high signal intensity in the medial temporal lobe and hippocampus (Fig. 1). Therefore, assessment of post-ictal signal changes and encephalitis was considered necessary. Examination of cerebrospinal fluid (CSF) and video EEG monitoring did not detect abnormalities. Conversion disorder was diagnosed and escitalopram $10 \mathrm{mg} /$ day and clonazepam $0.5 \mathrm{mg} /$ day were prescribed. In the initial interview, the patient displayed seizure-like movement in both arms and legs, and the interview was disrupted due to his selective amnesia. Although confusion and anxiety due to memory loss remained, the seizure-like movement gradually improved. Moreover, behavioral disturbances such as seizure like shivering and repetitive asking disappeared. Thus, the patient left hospital after 25 days.

Unfortunately, his problematic behaviors relapsed after discharge from the hospital. The patient performed repeated illegal behaviors including burglary, theft and a hit-and-run car accident. He did not recall some of the incidents. Moreover, he exhibited grandiose and violent behaviors, and was verbally abusive. Aripiprazole 30 $\mathrm{mg} /$ day or olanzapine $20 \mathrm{mg} /$ day with valproic acid 500 $\mathrm{mg} /$ day were prescribed in the outpatient clinic but his symptoms did not improve. Therefore, the patient was
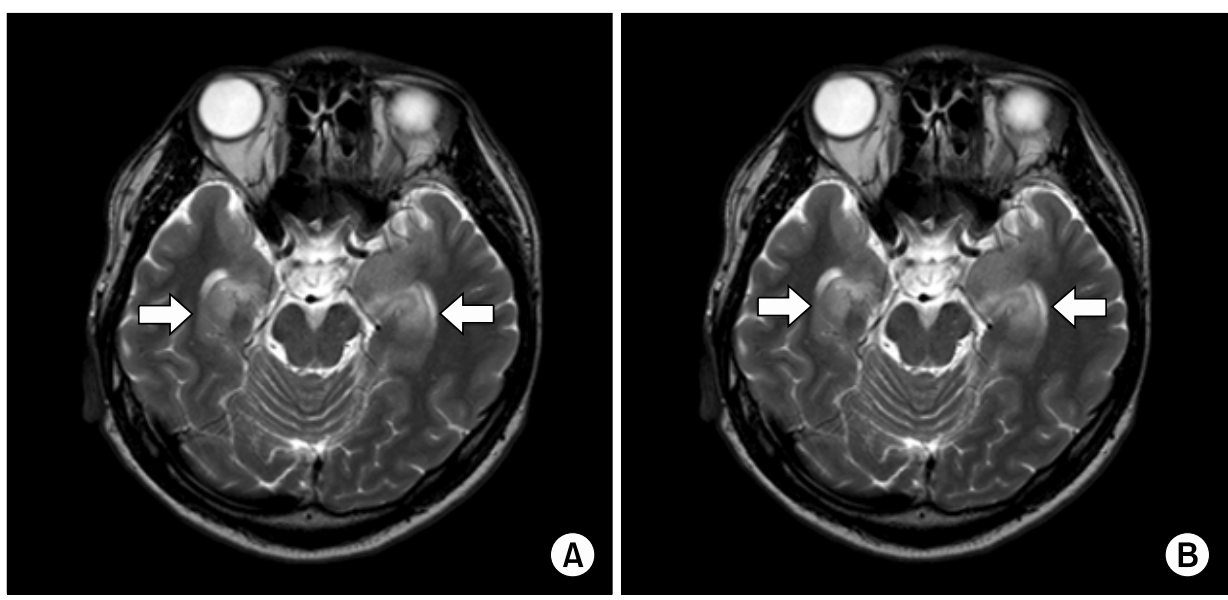

Fig. 1. Axial brain images of the patient. T2-weighted image show increased signal intensity in both medial temporal lobes and hippocampi at the first admission ( $\mathrm{A}$ and B).
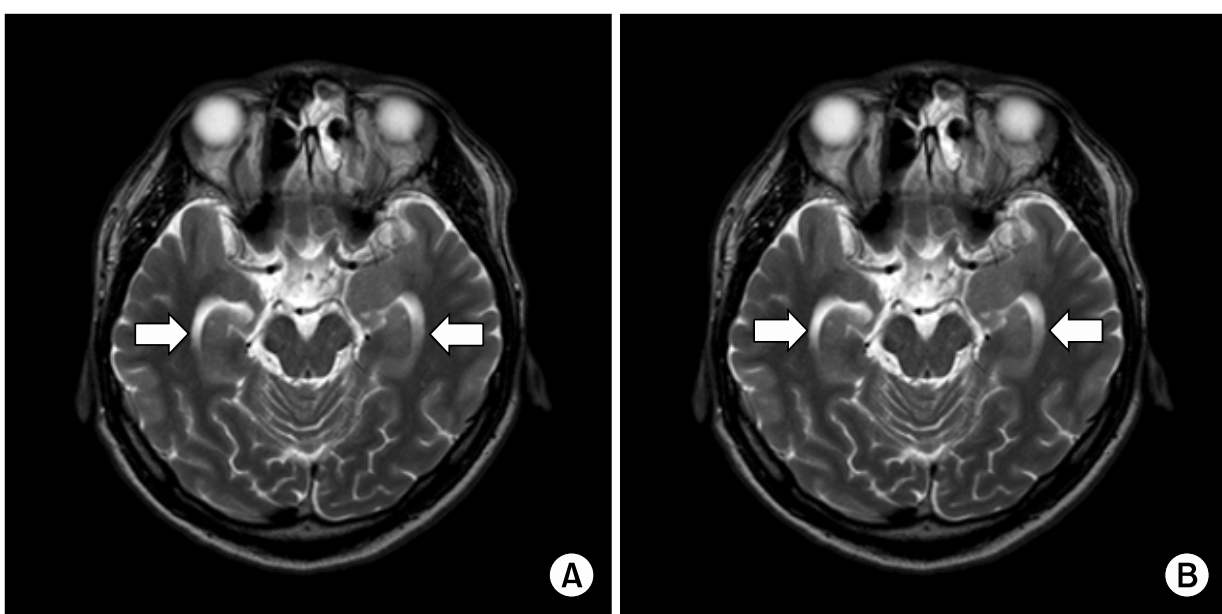

Fig. 2. Axial brain images of the patient. T2WI images demonstrated atrophy in both medial temporal lobes and hippocampi at the second admission ( $\mathrm{A}$ and $\mathrm{B}$ ). 
Table 1. A brief history of this case

\begin{tabular}{|c|c|c|c|}
\hline Follow-up day & Clinical manifestation & Evaluation & Results \\
\hline \multirow[t]{2}{*}{ Day 3} & \multirow[t]{2}{*}{$\begin{array}{l}\text { Selective amnesia, headache, seizure-like } \\
\text { activity }\end{array}$} & Brain MRI & $\begin{array}{l}\text { T2W high signal intensities in both medial temporal } \\
\text { lobes, hippocampi }\end{array}$ \\
\hline & & Brain SPECT & WNL \\
\hline \multirow[t]{2}{*}{ Day 7} & \multirow{2}{*}{$\begin{array}{l}\text { Seizure-like activity (jerky movement), } \\
\text { recent memory impairment }\end{array}$} & 24 hrs video EEG & WNL \\
\hline & & CSF study & WNL \\
\hline $\begin{array}{l}\text { Day } 25 \\
\text { (discharge) }\end{array}$ & $\begin{array}{l}\text { Conversion disorder c attacks or seizures } \\
\text { (diagnosis) }\end{array}$ & & \\
\hline $\begin{array}{l}\text { Day } 208 \\
\text { (2nd admission) }\end{array}$ & Selective amnesia, poor impulse control & $\begin{array}{l}\text { Brain MRI } \\
\text { Blood chemistry }\end{array}$ & $\begin{array}{l}\text { Atrophy in both medial temporal lobes, hippocampi } \\
\text { Hyponatremia ( } 131.9 \mathrm{mEq} / \mathrm{L})\end{array}$ \\
\hline Day 210 & $\begin{array}{l}\text { Selective amnesia, poor impulse control, } \\
\text { incoherence, hyperactivity }\end{array}$ & CSF study & WNL (consultation for autoimmune antibody study) \\
\hline \multirow[t]{2}{*}{ Day 217} & \multirow[t]{2}{*}{ GTC type seizure (45 sec) } & 24 hrs video EEG & Sharp wave, left temporal lobe \\
\hline & & Blood chemistry & Aggravated hyponatremia (122 mEq/L) \\
\hline Day 230 & Anti-LGI-1 limbic encephalitis (diagnosis) & $\begin{array}{l}\text { Autoimmune } \\
\text { antibody study } \\
\text { (CSF and serum) }\end{array}$ & Anti-LGl-1 antibody $(+)$ \\
\hline
\end{tabular}

MRI, magnetic resonance imaging; SPECT, single photon emission computed tomography; WNL, within normal limit; EEG, electroencephalogram; CSF, cerebrospinal fluid; GTC, generalized tonic-clonic; LGI-1, leucine-rich glioma inactivated-1.

re-admitted 208 days after discharge from his first admission, for more meticulous evaluation and symptom management.

During his second hospitalization, there were no signs of seizure-like movement, but selective amnesia and behavioral problems remained. Previous high signal intensity disappeared in a follow-up brain MRI, but bilateral hippocampal atrophy was detected (Fig. 2). On the ninth day of hospitalization, a generalized tonic-chronic seizure was observed for 45 seconds. Convulsive movement was not observed, but a sharp wave in the left temporal lobe was detected in video EEG monitoring. Nephrologists considered a possibility the syndrome of inappropriate secretion of anti-diuretic hormone (SIADH), since the initial sodium level was $131.9 \mathrm{mEq} / \mathrm{L}$. Blood sodium levels gradually improved to normal sodium concentration range with $7.5 \mathrm{mg} /$ day of the vasopressin 2 receptor antagonist, tolvaptan. The autoimmune studies in CSF and serum showed anti-LGl-1 positive reactivity. Classic paraneoplastic syndrome antibodies, such as anti-neuronal nuclear antibody 1 (anti-Hu), anti-Purkinje cell cytoplasmic antibody (anti-Yo), anti-neuronal nuclear antibody 2 (anti-Ri), anti-collapsing response mediator protein 5 antibody (anti-CV2/CRMP5) and anti-amphiphysin antibody were not detected. Moreover, autoimmune synaptic encephalitis antibodies including anti-NMDA, anti-AMPA1, anti-AMPA2, anti-CASPR2, and anti-GABA ${ }_{B}$ were not evident.
The patient was prescribed with oxcarbazepine 1,500 $\mathrm{mg} /$ day, lorazepam $0.5 \mathrm{mg} /$ day, and clonazepam 0.5 mg/day. Selective memory loss, generalized tonic-chronic seizure and behavioral problems improved, and he was discharged on day 25 following admission. The patient was referred to a neurological department for immunosuppressive therapy and upon the initiation treatment, and the patient was reassessed for anti-LGI-1 in CSF and serum. Although the result was anti-LGl-1 negative, the patient was treated with immunosuppressive therapy and was stabilized quickly. Table 1 chronicles the case. This case report was approved by the International Review Board of St. Vincent's Hospital, The Catholic University of Korea (VC16ZISE0033).

\section{DISCUSSION}

The patient showed selective amnesia and seizure-like movement without any infections or inflammations in the CSF examination and no epileptic form in EEG monitoring. The patient was speculated to have conversion disorder, but seizure-like movement did not improved by anti-depressant and anxiolytics treatment. Moreover, atypical anti-psychotics and anxiolytics treatment for symptoms, such as confusion or illegal behavior, were also useless. Medial temporal lobe atrophy in brain MRI and left medial temporal lobe epilepsy in video EEG monitoring were detected. SIADH was sus- 
pected due to decreased sodium levels (122 mEq/L), and blood sodium levels were improved by tolvaptan treatment. Interestingly, the symptoms improved after immunosuppressive therapy. Although the initial autoimmune studies showed positive anti-LGl-1 reactivity, reassessment before immunotherapy showed negative anti-LGI-1 reactivity.

Sero-negative limbic encyphalitis had been reported, ${ }^{7)}$ but our case cannot be explained by the aforementioned diagnosis due to one positive result for anti-LGI-1. A possible explanation for this phenomenon is change of antibody titer. Antibody disappearance in blood and decreased antibody titer in CSF were reported in case of anti-NMDA receptor encephalitis. ${ }^{8)}$ Symptoms of encephalitis might have fluctuated in accordance with anti-NMDA receptor antibody titer. Patient with sustained symptoms due to delayed diagnosis or immunotherapy can present with anti-NMDA receptor Ab positive results only in CSF and symptoms were improved with decreased $\mathrm{Ab}$ titer. ${ }^{8)}$ Our case showing contrary anti-LGl-1 reactivity, initial positive and subsequent negative results may be explained by the aforementioned case.

LGI-1 is a single human epilepsy-related gene encoding secreted neuronal protein. ${ }^{9,10)} \mathrm{LGl}-1$ mutation is related to autosomal dominant lateral temporal lobe epilepsy. This genetic syndrome causes hallucinations and partial seizures, but the incidence rate is very low. ${ }^{10)}$ The main role of LGl-1 in epilepsy is memory impairment and seizure. ${ }^{11)}$ The expression of $\mathrm{LGl}-1$ was reported even in kidney, and about $60 \%$ of anti-LGI-1 Ab AE present with severe hyponatremia. ${ }^{12)}$ In Thailand, prospective study of $103 \mathrm{AE}$ patients showed behavioral symptoms including psychosis (6/25 patients) and seizures (6/25 patients). Nevertheless, high suspicion for anti-LGI-1 Ab AE can be overlooked in patients with behavioral symptoms. ${ }^{13)}$ Therefore, Initial diagnosis can be confusing and can result in a delayed diagnosis of autoimmune LE. The therapeutic protocols for anti-LGI-1 antibody AE are not yet established. ${ }^{6}$ Recently, the effectiveness of steroid therapy in recurrent memory disorder by anti-LGI-1 antibody AE was described. ${ }^{14)}$ Moreover, immunosuppressive therapy can be more effective in cell surface antibodies including anti-NMDA, anti-LGl-1, anti-CASPR-2, antiAMPA and anti-GABA $A_{B}$ receptors than cellular antigens, which are classic paraneoplastic syndrome antibodies.

Three possible molecular functions of LGI-1 have been proposed. LGI-I prevents the inactivation of the Kv1 VGKC through the cytoplasmic regulatory protein $\mathrm{Kv} \beta{ }^{15)} \mathrm{LGl}-1$ regulates the neuronal development of glutamatergic circuits in the hippocampus. ${ }^{16)}$ Finally, LGI-1 interacts with the epilepsy-related AD-AM22/23 transmembrane proteins and regulates AMPA receptor-mediated synaptic transmission in the hippocampus. ${ }^{17}$ Recently, there have been reports of LGI- 1 autoantibodies specifically causing LE through inhibiting the ligand-receptor interaction between LGI-1 and AD-AM22 that controls AMPA receptor functions. ${ }^{18)}$ Nevertheless, the potential molecular mechanism of Anti-LGl-1 antibody $\mathrm{AE}$ is not yet been fully understood.

In conclusion, this case suggests differential diagnosis of $\mathrm{AE}$ should be conducted in a patient with atypical presentation of neuropsychiatric symptoms, such as memory impairment, personality change and seizure-like activity (with thorough review of medications that might have induced seizures ${ }^{19,20)}$ ), especially when other neurological diagnoses have been excluded.

\section{REFERENCES}

1. Wingfield T, McHugh C, Vas A, Richardson A, Wilkins E, Bonington A, et al. Autoimmune encephalitis: a case series and comprehensive review of the literature. QJM 2011;104: 921-931.

2. Thieben M, Lennon VA, Boeve BF, Aksamit A, Keegan M, Vernino S. Potentially reversible autoimmune limbic encephalitis with neuronal potassium channel antibody. Neurology 2004;62:1177-1182.

3. Han SW, Joo JJ, Kang JH, Ha SW, Yang YS. Non-paraneoplastic autoantibody-negative limbic encephalitis characterized by mild memory impairment: a case report. Dement Neurocognitive Disord 2014;13:79-82.

4. Vincent A, Buckley C, Schott JM, Baker I, Dewar BK, Detert N, et al. Potassium channel antibody-associated encephalopathy: a potentially immunotherapy-responsive form of limbic encephalitis. Brain 2004;127:701-712.

5. Lai M, Huijbers MG, Lancaster E, Graus F, Bataller L, Balice-Gordon R, et al. Investigation of LGI1 as the antigen in limbic encephalitis previously attributed to potassium channels: a case series. Lancet Neurol 2010;9:776-785.

6. Lancaster E, Martinez-Hernandez E, Dalmau J. Encephalitis and antibodies to synaptic and neuronal cell surface proteins. Neurology 2011;77:179-189.

7. Ahmad SB, Archer HA, Rice CM, Gerhand S, Bradley M, Wilkins A. Seronegative limbic encephalitis: case report, literature review and proposed treatment algorithm. Pract Neurol 2011;11:355-361.

8. Wandinger KP, Saschenbrecker S, Stoecker W, Dalmau J. 
Anti-NMDA-receptor encephalitis: a severe, multistage, treatable disorder presenting with psychosis. I Neuroimmunol 2011;231:86-91.

9. Gu W, Brodtkorb E, Steinlein OK. LG/1 is mutated in familial temporal lobe epilepsy characterized by aphasic seizures. Ann Neurol 2002;52:364-367.

10. Senechal KR, Thaller C, Noebels JL. ADPEAF mutations reduce levels of secreted $L G 11$, a putative tumor suppressor protein linked to epilepsy. Hum Mol Genet 2005;14:1613-1620.

11. Irani SR, Pettingill P, Kleopa KA, Schiza N, Waters P, Mazia C, et al. Morvan syndrome: clinical and serological observations in 29 cases. Ann Neurol 2012;72:241-255.

12. McQuillan RF, Bargman JM. Hyponatraemia caused by LGI1-associated limbic encephalitis. NDT Plus 2011;4:424426.

13. Saraya A, Mahavihakanont A, Shuangshoti S, Sittidetboripat $\mathrm{N}$, Deesudchit T, Callahan M, et al. Autoimmune causes of encephalitis syndrome in Thailand: prospective study of 103 patients. BMC Neurol 2013;13:150.

14. Noh KH, Kim SJ, Cho JW, Shin JH, Lee JH. Steroid responsive recurrent limbic encephalitis associated with LGI1 antibodies. J Korean Neurol Assoc 2014;32:91-94.

15. Schulte U, Thumfart JO, Klöcker N, Sailer CA, Bildl W,
Biniossek M, et al. The epilepsy-linked Lgi1 protein assembles into presynaptic Kv1 channels and inhibits inactivation by Kvbeta1. Neuron 2006;49:697-706.

16. Zhou YD, Lee S, Jin Z, Wright M, Smith SE, Anderson MP. Arrested maturation of excitatory synapses in autosomal dominant lateral temporal lobe epilepsy. Nat Med 2009;15: 1208-1214.

17. Fukata Y, Lovero KL, Iwanaga T, Watanabe A, Yokoi N, Tabuchi K, et al. Disruption of LGI1-linked synaptic complex causes abnormal synaptic transmission and epilepsy. Proc Natl Acad SCi U S A 2010;107:3799-3804.

18. Ohkawa T, Fukata Y, Yamasaki M, Miyazaki T, Yokoi N, Takashima $\mathrm{H}$, et al. Autoantibodies to epilepsy-related LGI1 in limbic encephalitis neutralize LGI1-ADAM22 interaction and reduce synaptic AMPA receptors. J Neurosci 2013;33: 18161-18174.

19. Bolu A, Akarsu S, Pan E, Aydemir E, Oznur T. Low-dose clozapine-induced seizure: A case report. Clin Psychopharmacol Neurosci 2017;15:190-193.

20. Itil TM, Soldatos C. Epileptogenic side effects of psychotropic drugs. Practical recommendations. JAMA 1980;244:14601463. 